\title{
الجغرافية بين الواقع والوظيفة
}

\section{Career\&Geography between Reality}

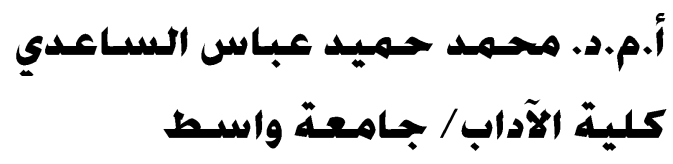

Abstract:

The diverse scientific knowledge is fused into the crucible of place and geography, as it had a significant impact in the Development of human Civilization with different knowledge.

It was a product that meets the needs of Humanity in different fields of life and critical times, which takes on a fateful character.

On the other hand, it was necessary to develop the skills of Applied Geography, being the practical aspect that meets the needs of the market and the different institutions. However, the geographers stuck to abstract theoretical branches and considered pure disciplines without paying attention to the useful side of this science, has increased the monotony of local geography, So practical application is bring the theory to reality, and to get benefit from it, to rise to the level of law, to achieve the basic principles of science (Prediction \& Generalization), and to take advantage of the comparison in this aspect.

The attempts of the Iraqi geographers to develop and bridge the gap in this subject are part of their initiatives to promote applied geo-studies in many academic institutions and to adopt them as specialized departments in an attempt to break the barrier of monotony and seduction, Which is the intended target, to integrate with spatial science into an integrated unit and that will be an important project to solve the problems of the modern area in the country with the latest technologies used in these science.

الإقدمة

من اللافت للنظر، أن يعرف علم مـا، بأنـه "علم التخصص في غير التخصص! "، ويعد مـن التعريفات الهامـة لعلم الجغر افية، إذ يؤكد على الطبيعة التركيبية لهذا العلم، التي تتداخل فيها أفرع الجغر افيـة المختلفة، الطبيعيـة منها او البشرية، باعتبار إن الجغر افية تدرس وتحلل البيئة بكل مكوناتها، وهذا الأمر لم تتناوله العلوم الأصولية الأخرى بسبب محدوديـة طبيعة تخصصاتها. فالتفسير المنكامل للعديد من الظاهر ات البشرية والطبيعية وفق المفهوم المتكامل للجغر افيـة هو احد الأمور التي ميزته بشكل كبير عن غيره. وتصنف العلوم بشكل عام إلى ثلاثة مجموعات أساسية إذ نشمل المجموعة الأولى العلوم الطبيعية كالكيمياء و الفيزياء و علم الإحياء و النبات. في حين تشمل المجموعة الثانيـة العلوم الرياضية، و التي تبحث في الكم و الخو اص المجردة. و المجمو عة الثالثة تضم العلوم الإنسانية و الاجتماعية كعلم النفس والاجتماع والاقتصاد. وهنـا وبين تلك المجاميع من العلوم لا يمكن أن نضع الجغر افية تحت أي مظلة منها فهي ليست طبيعية صرفة، و لا كمية مجردة و لا اجتماعية صرفة. و إنما هو حلقة وصل بين تللك العلوم في نسق واحد تتفاعل فيه البيئة الطبيعية مؤثرة في الإنسان ومتأثرة به، بحيث يخرج في النهايـة مركب جغر افي متكامل ناتج عن هذا التفاعل بين المكونات الطبيعية والبشرية للبيئة الجغر افية.

إن النظـرة الضـيقة التي ينظر هـا الدارسـون المحليون مـن غيـر ذوي الاختصـاص إلى هـا العلـم، وتهميش أدبياتــه ومخرجاته العلمية في سوق العمل، ومفاصل مؤسسات الدولة، وطبيعة المجتمع العربي عامة والعر اقي خاصة، بسبب نوجهاتهـ المادية البحتة، تدفعنا إلى التساؤلات الآتية:

هل أصبحت الجغر افية كعلم غير ذي نفع في العالم المعاصر وهل تعد مخرجاته عبارة عن بطالة مقنعة؟ هل نرنقي الجغر افية كعلم من النظرية إلى التطبيق ثم إلى الواقع العملي ؟ 
هل تختلف الجغر افية في تطبيقاتها ومناهجها في الغرب عنها في الشرق وأصبحت فاعلة في مجتمعاتهج؟ هل يوجد خلل في منظومة دراسة وتدريس علم الجغر افيـة في مؤسساتتا الأكاديمية وبالتـالي تتأتر مخرجات هذا العلم وتكون بعيدة عن متطلبات سوق العمل؟ وللبحث و التقصي عن الإجابات لابد لنا أن نتصور الإجابات بشكل افتر اضي وكالآتي: إن الدراسات الجغر افية في العراق قسم منها نظري وقسم آخر تطبيقي إلا أنها لا ترقى إلى حاجـة الواقع و لا تلبي سوق العمل إلا في الجانب التعليمي.

يعد الو اقع العملي أصل الدراسات الجغرافية القديمة والمعاصرة، وهي من الأهمبة الكبرى في الدول المتقدمة اقتصاديا. هنالك اختلاف كبير في طرق ومناهج و أساليب العمل في علم الجغر افية الغربية والعالمية عنها في الدول العربية. هنالك حلقات مفقودة في أسلوب وتقنيات التدريس الجغر افي في الجامعات العربية والعراقية، الأمر الذي سبب فجوة كبيرة بين النظرية و الواقع العملي.

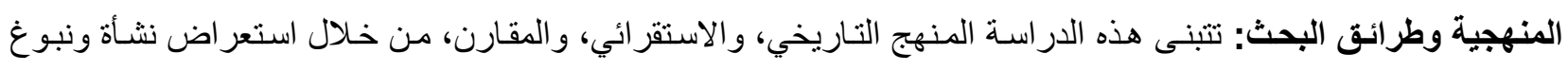
علماء الحضار ات القديمة في هذا الميدان، وطرق البحث الجغر افي لديهم، بحيث أصبحت تلألك الدراسات أساسا لكثير من العلوم

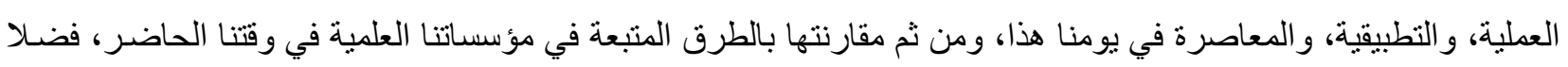
عن إظهار الجوانب المتنو عة من فروع الجغر افية و أهميتها العلمية و العملية.

\section{أولا الجغرانية موضوعها أهدانها:}

مـا الجغر افيةه؟ تبدو الإجابة على هذا السؤال محيرة سو اء لمن ينتمون لهذا العلم أو لمن لا ينتمون، ويتمثل مصدر تلك

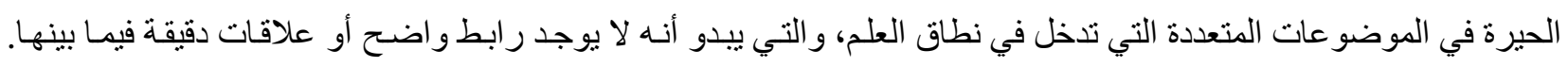

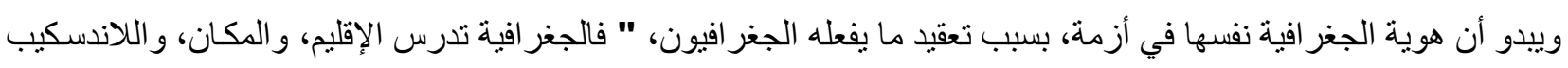

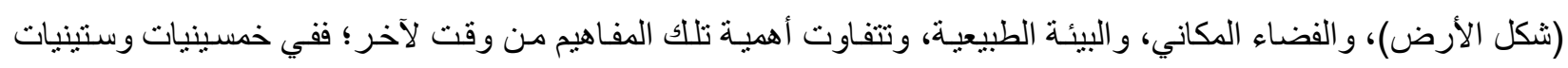

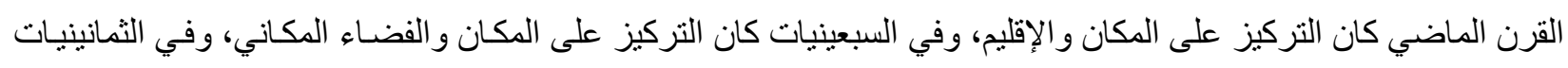
كان التركيز بشكل أكبر على البيئة الطبيعية، نظر التنامي الوعي بمفهوم الكوكب العالمي الذي تتهدده مخاطر البشرية. آخذا في الإني

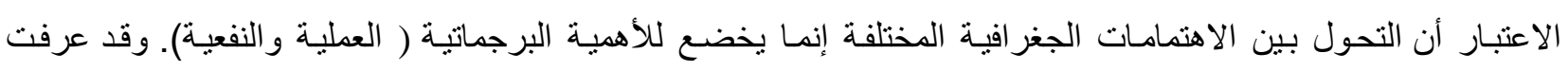

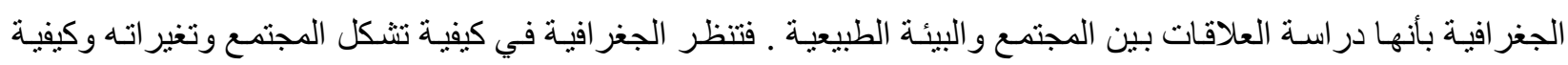

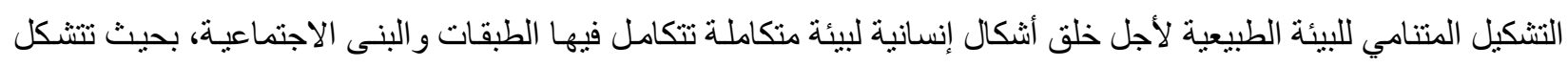

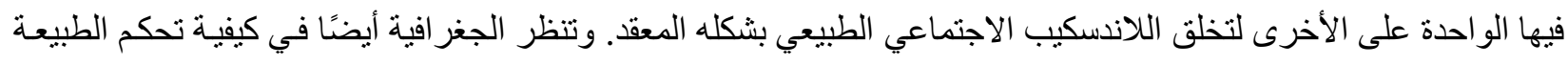

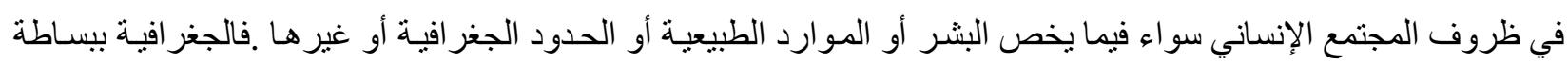

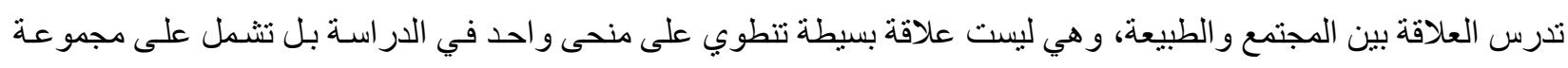

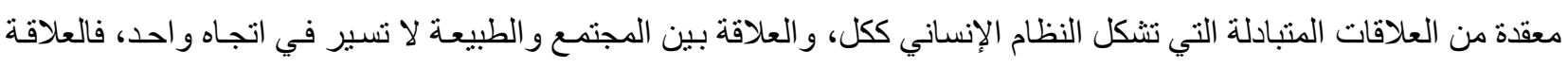
السبيية التي تؤسس للتغيرات الاجتماعية على أساس الظروف الطبيعية تحولت في اتجاه معاكس لتؤكد على نأثر البيئة الطبيعية

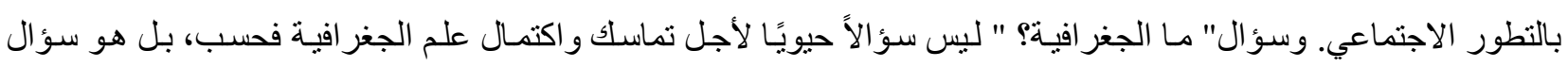

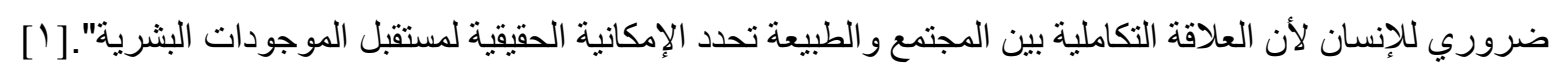


وقد بالغ بعض الجغر افيين في أرجحة تأثير تلاك العلاقة، مثل همبولت الذي جعل الإنسان و النشاطات البشرية انعكاسـا تاما للظروف الطبيعية، وتفسير أخلاقيات وسلوك وطبائع السكان، وأنماطهم الاقتصادية، والاجتماعية، كتعبير مباشر عن تأثثير

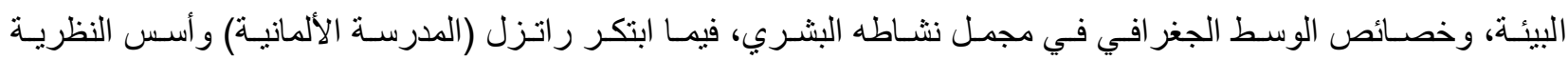

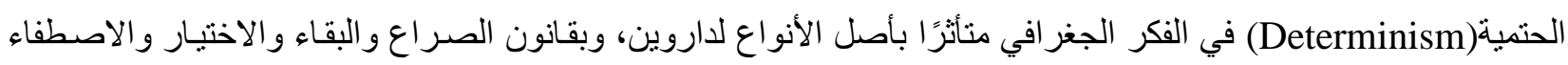

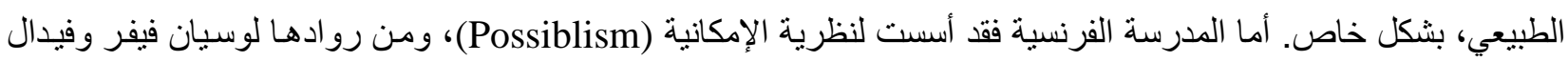
دي لابلاش وهي في مضمونها تثبر إلى قدرة الإنسان على تسخير الطبيعة وترويضهـا لصـالحه. إمـا المدرسـة السوفيتية فـان

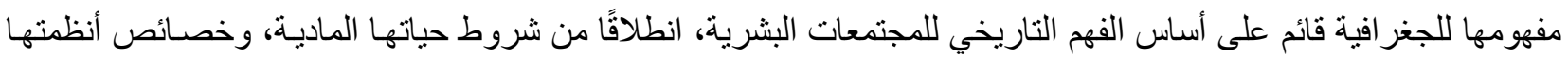
الاقتصادية، وقوى الإنتاج، و علاقات الإنتاج المتوافقة معها في خلق المفاهيم والإيديولوجيات العامة، التي تنؤثر بشكل فعال في تئي

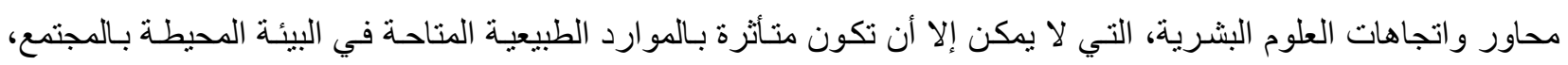

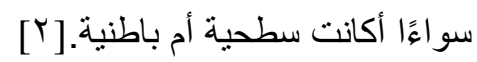
مـا موضوعها؟ من خلال مـا تقدم يمكن القول إن الجغر افيـة تتتـاول عدة جو انب ولكن بصورة رئيسـة هنالك جانبـان مهمـان؛ الأول هو الجانب الطبيعي، والثاني هو الجانب البشري، أضف إلى ذلك، حالة التفاعل (العلاقة) بين الثقين السابقين، والتأثير

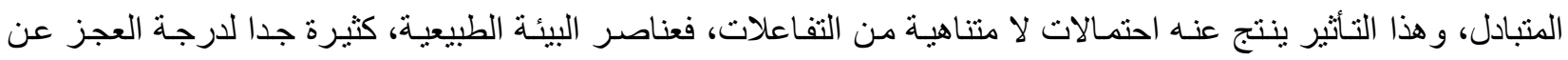

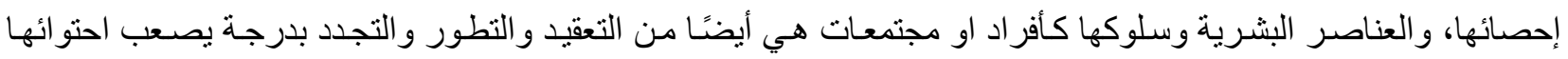
و التنبوء بها، لذا فـان التفاعلات البشرية والمجتمعية مع العناصر البيئية المختلفة غبر محدودة، وكذا الحسال نتائجها، إلا أننا نستطيع أن نورد البعض منها على سبيل المثنال لا الحصر : فمن مواضيع الجغر افية الطبيعية

دراسة الغلاف الصخري من خلال در اسة تركيب الأرض الداخلي ودراسة صخور القشرة الأرضية بأنو اعها المختلفة ومعالجة

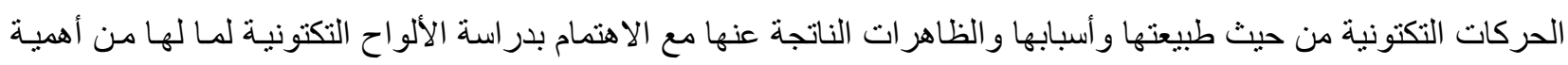
في تفسير العديد من أثنكال سطح الأرض. در اسـة عو امل تثكيل سطح الأرض و العمليـات المرتبطـة بها و الأشكال الناتجـة عنهـا كالتجويـة و العمليـات المرتبطـة بتطور

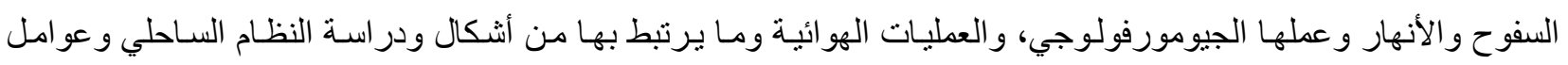
التشكيل داخله واهم الظاهر ات به.

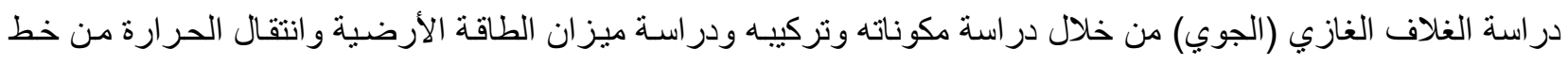

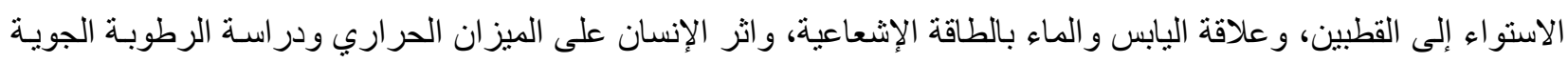
و الرياح وما يرتبط بها من ظاهر ات جوية فضلا عن دراسة هذه العناصر لمدة طويلة من الزمن فتكون دراسة المناخ. دراسة الغلاف المائي في كل من المحيطات و الغطاءات الجليدية و المياه الجوفية والمسطحات المائية المختلفة. در اسة الغلاف الحيوي من خلال التعرف إلى عناصره ودر استها بالتفصيل و علاقتها بدورتها مع سطح الأرض، ودر اسة النظم البيئية من حيث مفهومها وضو ابطها وخصائصسها من حيث الثكل و التنوع في عناصر ها الحيوية فضـلا عن در اسـة التربـة

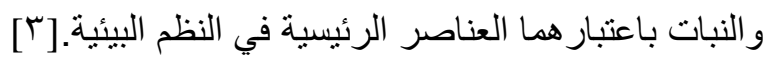

در اسة الأجرام السماوية من حيث ما تقدم و إمكانية العيش وتوزيعها وتركيبها و أهميتها الاقتصسادية والإنسانية. كذلك من المواضيع التي تهنم بها الجغر افية البشرية 
در اسة وتحليل السكان من حيث النمو و التوزيع و الكثافة والخصوبة و الوفيات و الهجرة و العو امل المؤثرة فيها. دراسة وتحليل المظاهر البشرية كالصناعة والتجارة و النقل و الزر اعة والاتصالات والمواصلات و الحضر و الريف. در اسة الموارد الطبيعية باعتبار ها جزءا من الجغر افية الاقتصادية ، و العوامل المؤثرة في استثمار الموارد الطبيعية فضلا عن مصادر الطاقة. دراسة وتحليل التلوث البيئي الناجم عن النشاطات البشرية والطبيعية والصيد الجائر للثروة الحيو انية البرية والبحرية. در اسة وتحليل مشكلات تامين الغذاء و الماء في العالم. [ع] در اسة وتحليل تاريخ و اصل الظو اهر الجغر افيـة الطبيعية و البشرية ومحاولـة فهم طريقة تكونها وتغيرهـا ونموهـاو اندثار ها و العوامل التي أدت إلى ذلك.

ما أهداف الجغرافية؟ كثيرة هي أهداف هذا العلم نظر السعة حقوله و البيئة التي يتناولها في دراسـاته و أدبياته فمثلا يهذف إلى:

الفهم، فهو نشاط إنساني يهدف إلى فهم الظو اهر المختلفة وتفسيرها انطلاق من حقيقة إن وصف الظاهرة لا يضاهي في أهميته معرفة كيفية حدوثها وأسبابها، و الفهم يؤدي إلى الكثف عن القو انين الحاكمة التي تتحكم بالظاهرة، بشرية كانت أم طبيعية. التتبؤ، و هو تصور النتائج التي يمكن أن تحدث، إذا ما طبقت القو انين التي تم اكتشافها، على مو اقف جديدة، فتمكن الباحث من

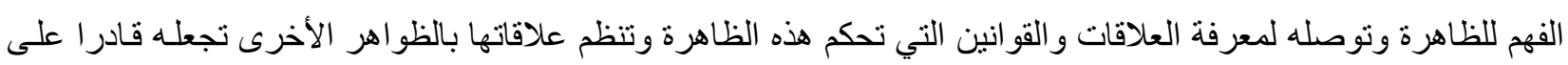
التنبؤ.

الضبط، ويعني التحكم بالعو امل الأساسية التي تسبب حادثا مـا لكي تحمله على التمام او تحول دون وقوعه، ويتوقف الضبط

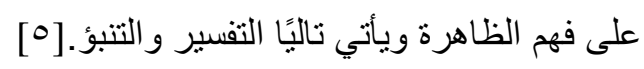
در اسة وتحليل التباين المكاني و الزمني على سطح الأرض و الأسباب في ذلك و النتائج بهدف التنبؤ.[?] التحليل المكاني للظو اهر المختلفة طبيعية كانت أم بشرية للتعرف إلى الأسباب و النتائج. التعرف إلى وظيفة الظاهرة و إبعادها محليا او إقليميا وتأثير اتها به من جهة وبالظاهرة من جهة أخرى. در اسة الأقاليم وخصائصها الطبيعية والبشرية كظاهرة متكاملة لها وظيفتها المميزة و التعرف إلى أبعاده ومميزاته.

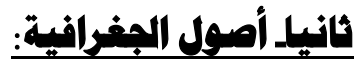

تشير الدراسات المناخية إلى أن حلول العصور الجليدية في النصف الثمالي من الأرض، وبالتحديد في شمال ووسط

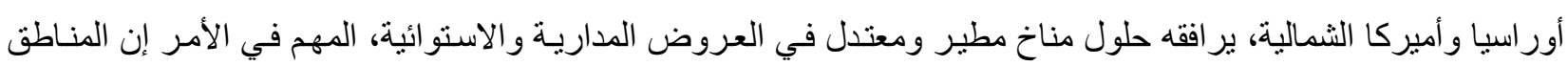

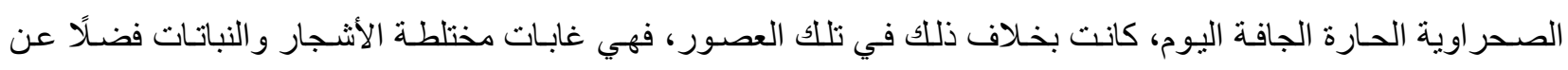

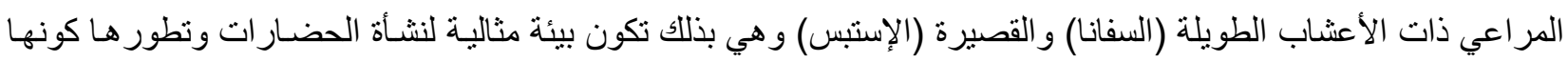
حضار ات قائمة على الزراعة بالارجة الأساس.

إن حضارة وادي الر افدين (السومرية ثم البابلية)، من أقدم الحضـارات التي عرفت، حيث كانت الزر اعـة عمودهـا

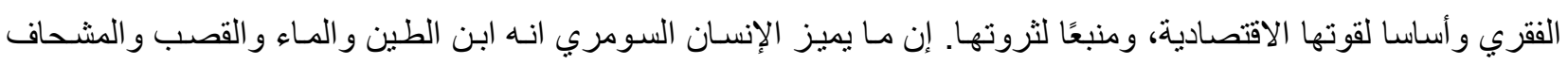

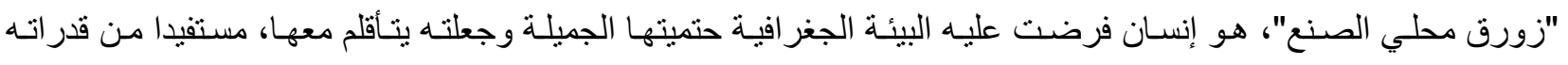


المعرفيـة بها، بـان طوع عناصـر ها لصـالحه، فكانت الإمكانيـة فاعلـة في عملـه وفكره، ومـن هذه العناصـر (الطين والمـاء

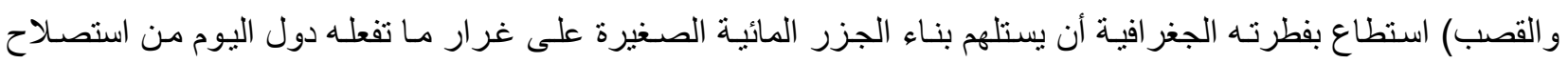

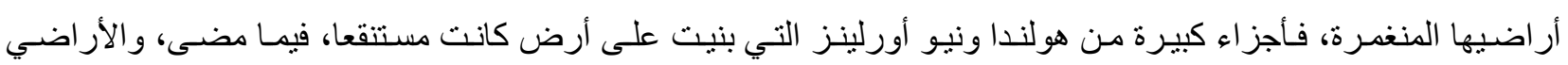

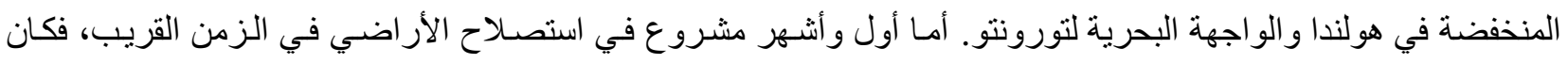

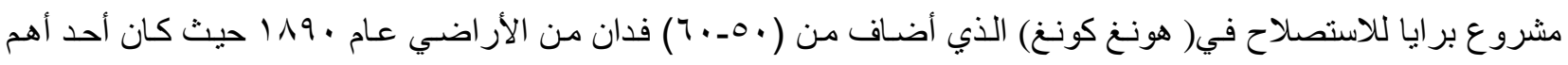

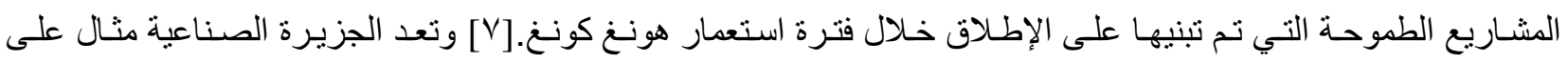

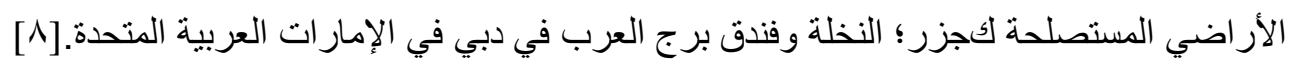
بهذه التقنية تمكن الإنسان السومري من تطويع بيئته واستغلالها وبناء المدن وزارعة القمح وتربيـة وتدجين الحيوانات

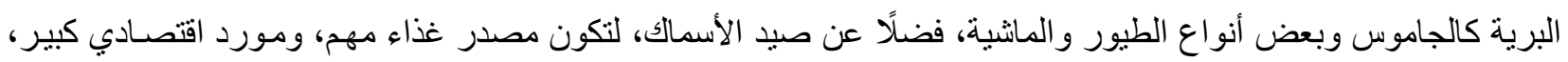
فبدئت الحياة الحضرية بعد أن تكدست البيوت القصبية واكتظت بالسكان، ولحمايتها من الأخطار الخارجيـة، بُنَيَت الأسوار

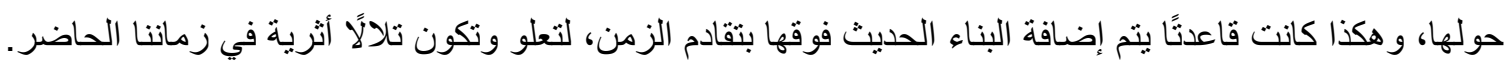
من أهم تلك الحاضرات مدن؛ أوروك، ونفر ، وأور، وأريدو، و لارسـا، وبابل، وكوتي، وكيش، ولكش. إن الظروف

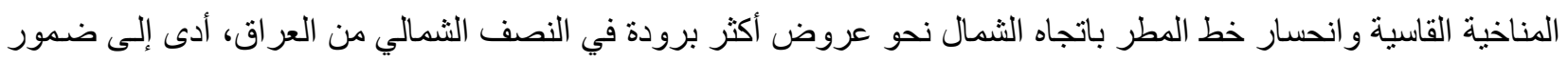

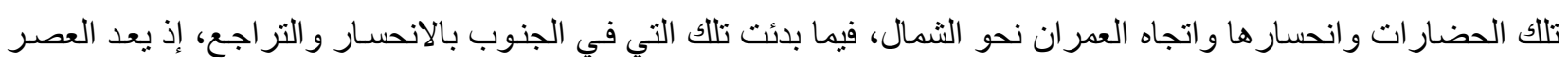

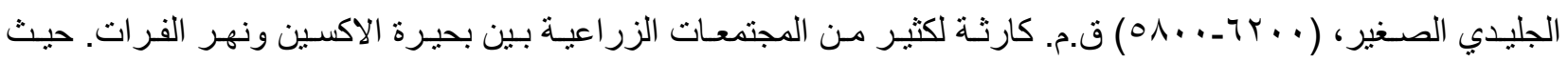

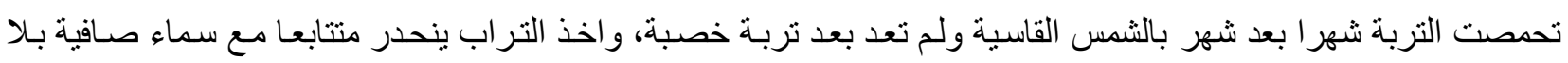

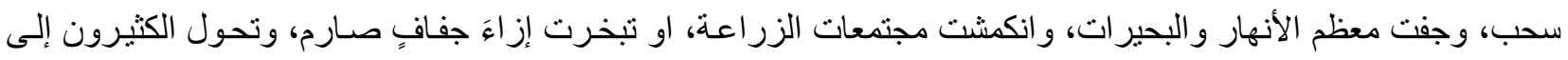

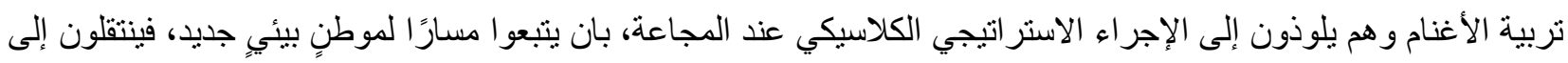

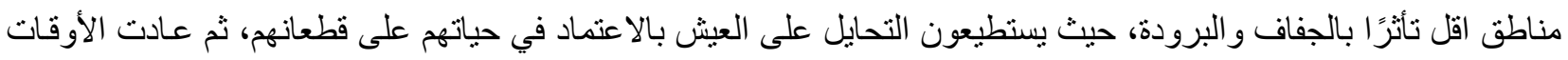
الطيبة في . . 10 ق.م. حيث انضغط زر تشغيل دورة الأطلسي وعادت فجأة الرياح الغربية للبحر المنوسط المحملة بالأمطار.

إن الفطرة، والتجربة، و المعرفة المناخية، والخبرة الميدانية بالري واستصلاح الأراضي، للسومريين و البابليين، فضلً

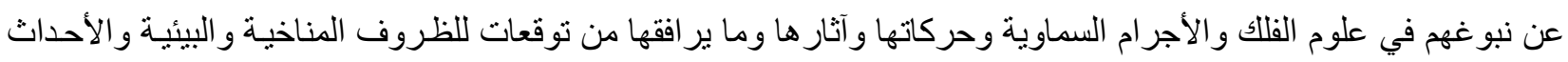

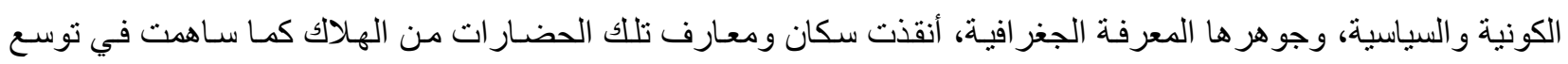

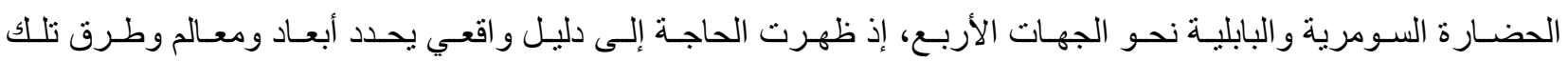

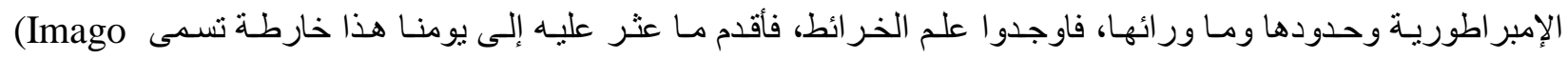

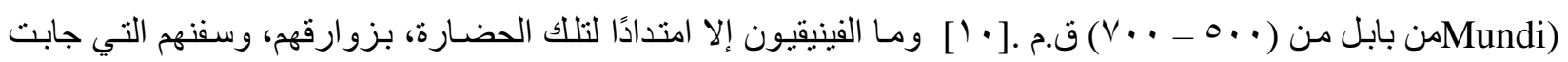

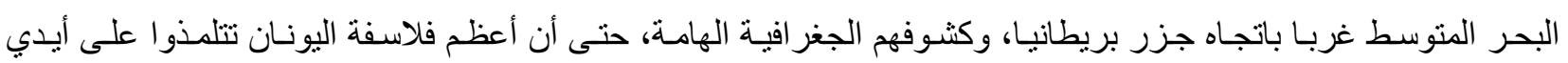

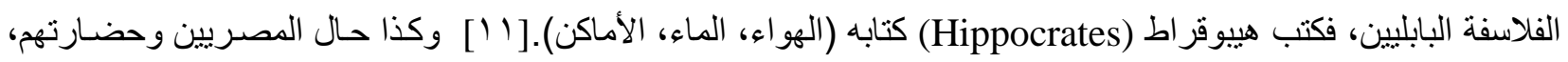
إنما هي امتدادًا لبابل، بأهر اماتها ومعابدها وجنائنها المعلقة وزقور اتها ونظمها التشريعية و الاقتصادية و الزر اعية ومو اد بنائها

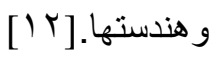


خلاصة القول أن هذه المعارف التي انصهرت في بوتقة علم المكان و الجغر افية كان لها وقع كبير في نشوء وتطور

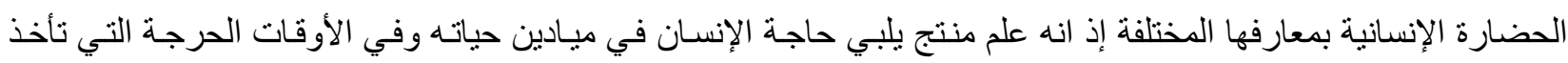

طابعا مصيريا.

\section{ثالثـ أنواع علم الجغرافية}

1ـ الجغرافية النظرية Theoretical Geography: في حقيقة الأمر أن أدبيات الجغر افية ومفاهيمها مستقاة من

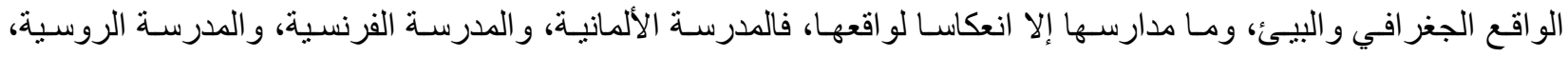

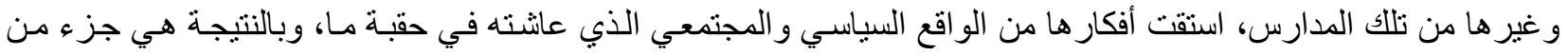
المدرسة الثمولية لعلم الجغر افية، إلا أن الاقتصار على الجانب النظري من هذا العلم ضمن قاعات الدرس المغلقة لا يعد علمًا و اقعيا، و لا يسلح الدارس بمهار ات الجغر افي الحذق، فاستعر اض التاريخ الجغر افي وفكره و أقسامه وقوقعة المتلقي بين غلافي سلي الكتاب يعد درسًا في الحفظ و الترديد، إن مختبر الجغر افي هي الطبيعة، و الو اقع، و المدينة، والريف، و المياه، و الجبال وبيئته

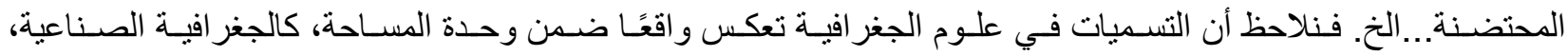
و الزر اعية، و المناخية، و الطبية، و الخدمية، و النسوية، و الجيو مورفولوجية، وجغر افيـة البحار و المحيطات، و الموارد المائية، و غير ها. إذ إن الجانب العملي كان الأصل في إيجادها ومصدر أدبياتها.

r- الجغرافية التطيقية Applied Geography: جائت هذه التسمية لتحقيق الجانب التطبيقي من الدراسـات الجغر افيـة النظريـة فـثنا يهدف علم المنـاخ التطبيقي (Applied-Climatology) إلى تسخير الدراسـات المناخيـة وبياناتها

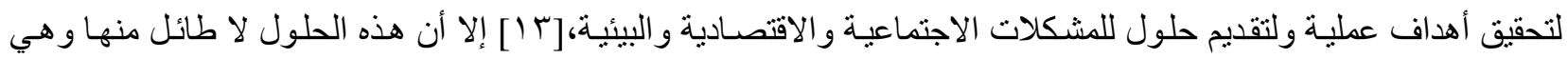
مجرد در اسات على ورق، وكذا الحال مع الجيومورفولوجيا التطبيقية Applied-Geomorphology) التي تهتم بتطبيق طرق استخدام المعايير والمقاييس لدراسة العمليات الجيومورفولوجيا ومسح المظاهر الناتجة عنها، وتحليل البيانات المستقاة من تللك الدر اسة، من اجل تخمين وتقييم الثروات الطبيعية المتو اجدة في منطقة ما ومدى إمكانية استغلال تلك الثروات. [ع إن فيما

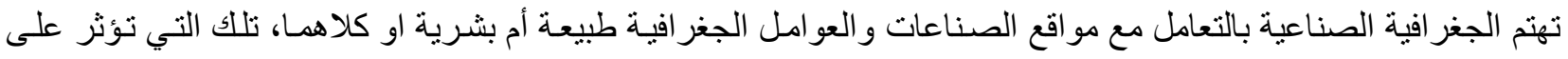
موقعها وتطور ها و المو اد الخام المستخدمة فيها ونوزيع منتجاتها النهائية.[0 10] و الحال نفسه في الجغر افيـة الزراعية وجغر افيـة الحضر و الريف وجغر افية الخدمات المختلفة ...الخ. أما الجغر افيـة السياسية و الجيوبولوتكا برو ادهـا، فكانت من الخطورة في تحديد وجهة التحركات الاستعمارية، والسيطرة على العالم في القرنين المنصرمين، إذ أخذ المفكرون الألمان الريادة لدراسـة العلاقة القائمة بين العو امل الجغر افية، وطبيعة الحركة السياسية للدولة، فكان كارل ريتر واحدا منهم؛ إذ كان يعتبر ظروف السطح و المنـاخ مؤثرًا مباثـرًا على الحركات البثرية وتاريخ الثـعوب. وقبيل الحرب العالمية الأولى ظهر العالم السويدي

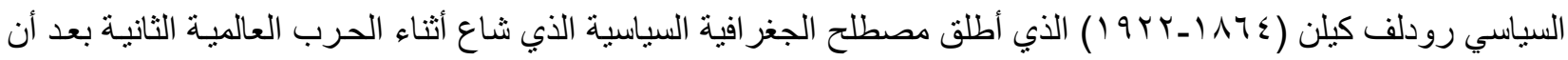
طور من عدد من الباحثين كان أبرزهم المفكر السياسي الألماني كارل هاوس هوفر الذي بنت ألمانيا النازيـة تطلعاتها السياسية

إن جلُ التعاريف توضح ماهية فروع علوم الجغر افية، التي تصب مجملها في تحقيق خدمة الواقع العملي، لتسهيله إلى البشرية، وتفادي المعوقات المختلفة. وهي في ذلك من العلوم الوظيفية العطلية، فلو لم تلك كذللك، فهي من العلوم غير النافعـة،

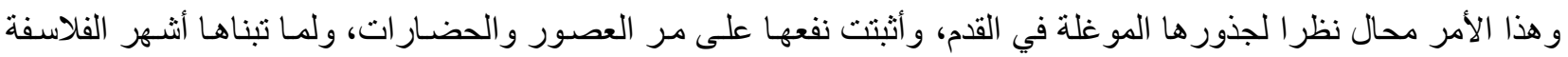


rـ الجغرافية العملية Practical Geography: وتهتم بخصائص كوكب الأرض من حيث الثكل والخصـائص الهندسية،

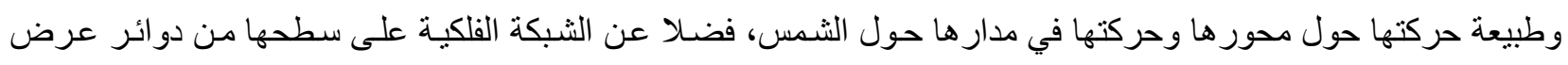

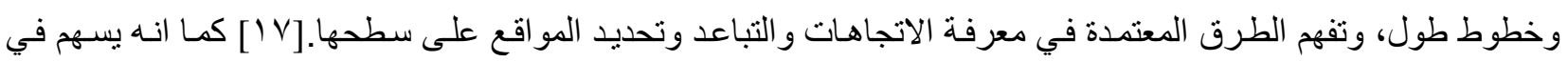
مجال الاتصالات، ويظم نظام العمليات الجغر افية (Geographic Operations System) في عملية تكامل البيانات لقدرة

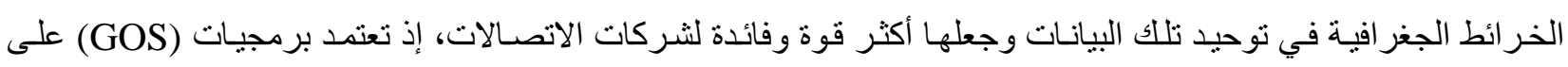

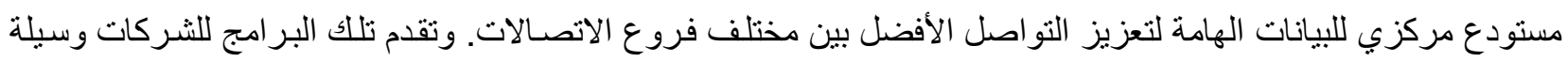
لتحقيق التقارب التكنولوجي في منتجاتها المسوقة. ودفعت الضغوط المنز ايدة للمنافسة و التوسع في سوق الاتصـالات العديد من ون

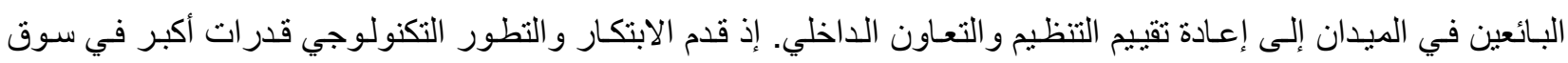

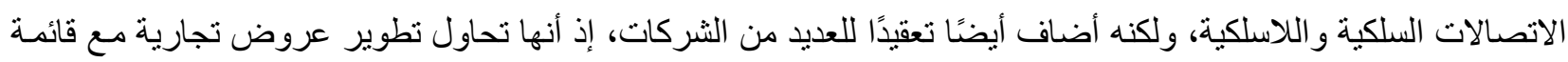

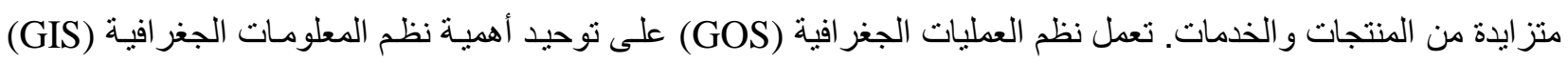

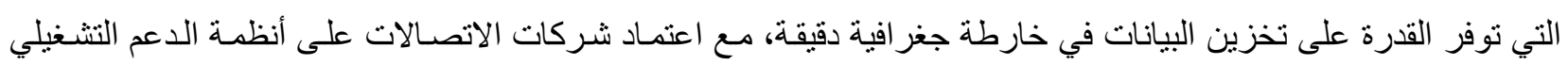

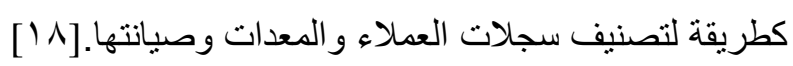
إن هذا الفرع من الفروع المهمة جدا، وله ارتباطا وثيقا بشركات الاتصالات و المساحة و الهندسة و التخطيط العمر اني

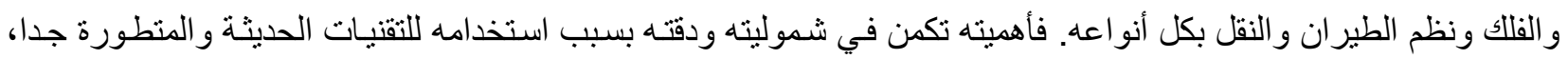

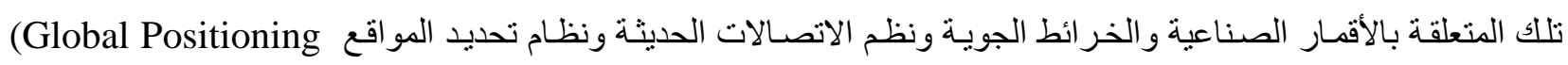
.System) رابعا- الجغرافية والعلوم المكانية (Spatial Sciences): إن مفهوم المكان مرتبط في ذهن الكثيرين بالجغر افية، إذ إن العديد

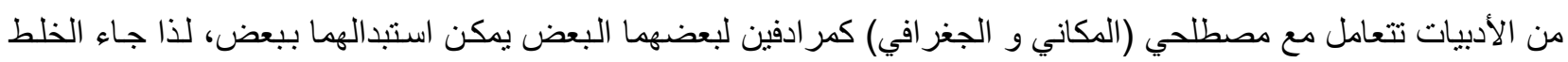
بين ما هو مكاني وما هو جغر افي. وفي الوقت الذي تتجه مختلف العلوم إلى استحداث تفر عات تخصصية دقيقة لها، فإنها تميل لهيل في الوقت ذاته إلى التجمع حول موضو عات تمثنل اهتمامـا مشتركا مـع غير هـا، ولهذا تشكلت أقساما وكليات علميـة بتسميات

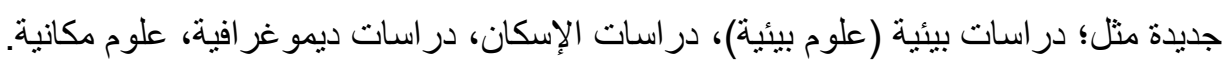
قد تبع ذللك، إعادة النظر في الهيكلية التنظيمية للعديد من الجامعات، لِنُجمَع التخصصـات المتقاربـة مـع بعضها تحت إدارة موحدة نتيجةَ تكاملها المعرفي، و نوحيدًا لمنهجها البحثي، وتسهيلا لخدماتها الإدارية. وتظم علوم المكان (Sciences-Spatial) طيفا واسعا من التخصصات العلمية، مثل الجيولوجيا و التفرعات الهندسية

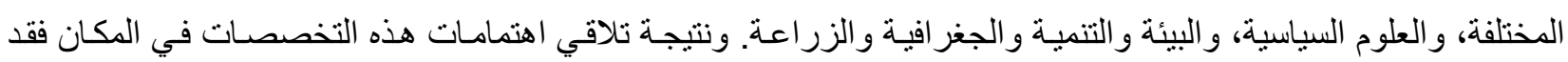

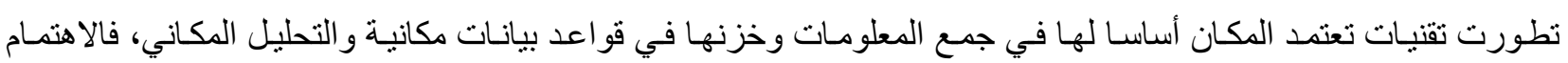
المشترك بالموضوع قد أدى إلى التعاون لنطوير أدوات واستحداث ما يحتاجه الباحث ويسهل عمله، وبالمحصلة النهائية تقارب

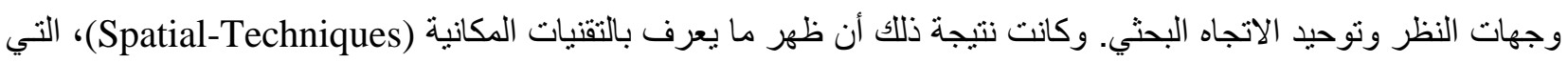

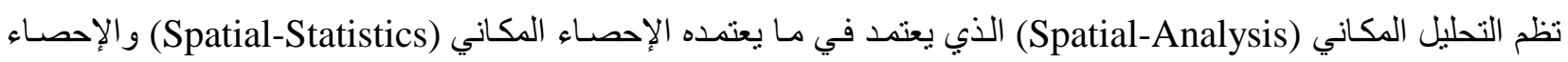
الجغر افي-المكاني (Geospatial-Statistics) و المنظور المكاني (Spatial-Approach) وكذلك تكونت نظم قو اعد بيانات مكانية، رافقتها برمجيات تعتمد المكان أساسا لها مثل نظم المعلومات الجغر افية و الجيوماتيكاو ا و الاستشعار عن بعد و غير هـا،

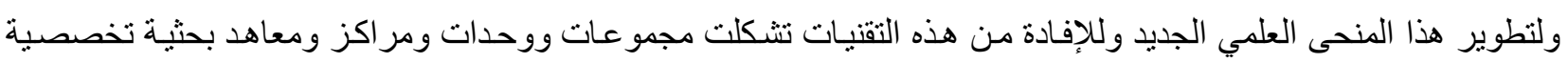
تعنى بها مثل؛ مركز التحليل المكاني في جامعة اوكلوهاما، ومركز تكامل العلوم الاجتماعية المكاني في جامعـة كاليفورنيا، 
ومجمو عة التحليل المكاني في جامعة كاردف، ومثلها في جامعة موناش، ومعهد التخطيط المكاني في جامعة دورتموند التقنية،

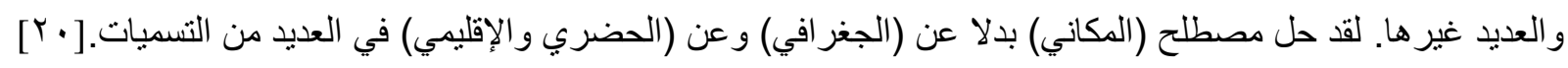
خامسا- الجغرافية والتقنيات الحديثة (Modern Techniques): إن إمكانيات اتخاذ القرار ات الصحيحة في الوقت المناسب

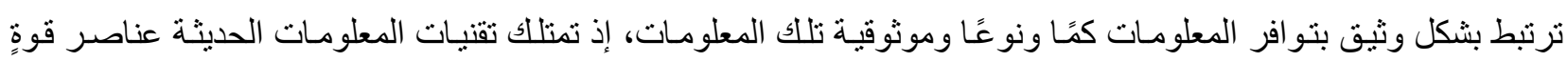

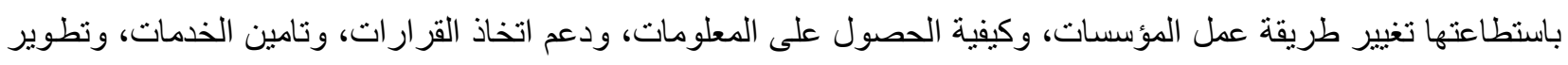

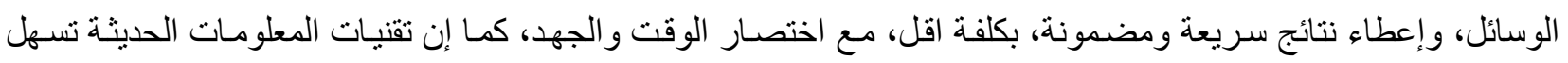
عملية الوصول إلى المعلومات، والبيانات، وتبادلها، وأيضا تحسين الطرق التي تتبعها المؤسسات لتقييم وحل المشكلات. ومن أهم خصائص علم الجغر افية الحديثة، التجدد ومو اكبة التطور بغية الاستفادة وتحقيق النظرة الجغر افيـة الثمولية

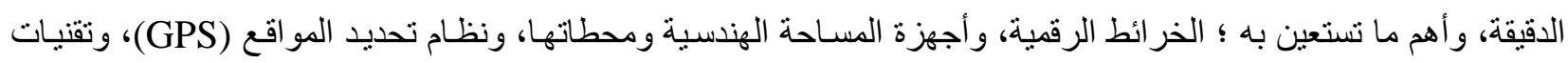

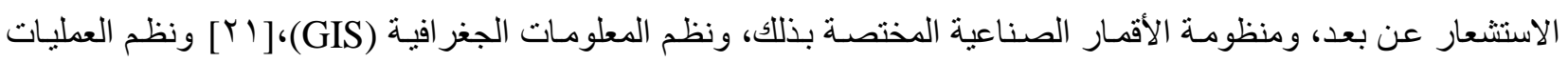
الجغر افية (GOS)، وأجهزة تحليل وقياس التربة و المياه، وأجهزة حساب تلوثها، و أجهزة تحليل الصخور و المعادن، و أجهزة رصد عناصر الجو والمناخ، ومحطات رصد التلوث الجوي...الخ. هذه التقنيات تجعل من الجغر افية علمًا حاضرًا وفاعلًا بقوة في ميدان العمل، وصناعة القرار، وتعزز مكانته المرموقة بين العلوم، باعتباره علما بينيًا شموليا. سادســ الجغرافيـة المعاصرة Geography) : Contemporary) إن التوجهات التوسعية والاستغلالية للعسالم من قبل القوى المتصار عة و المسيطرة على مقدرات العـالم خلال القرن الماضي كانت سببا في تطور علم الجغر افيـة وتتامي تقنياتـه بصورة أساسية، إذ أُنِجتت العديد من المدارس الجغر افية، كالمدرسة الألمانية، و السوفيتية، و الفرنسية، و اليابانية، و الانكليزيـة،

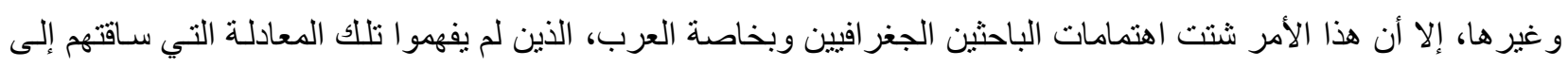

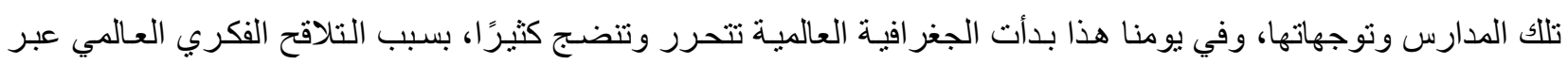

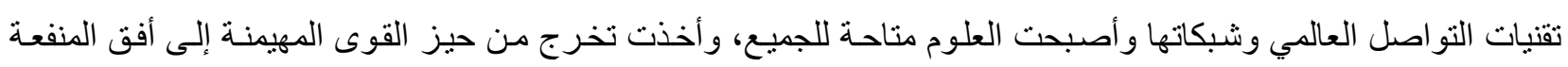

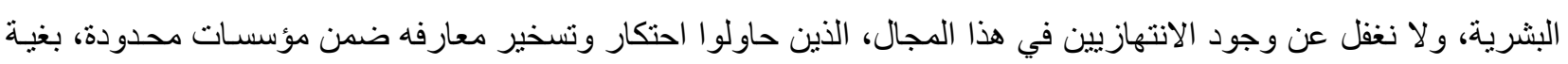

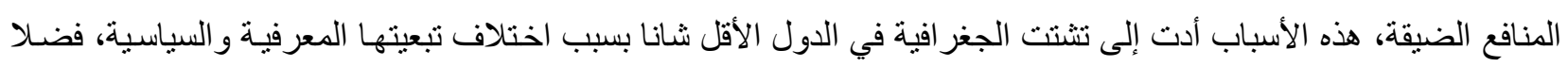

$$
\text { عن الهوة المعرفية. }
$$

ويمضي عمل واهتمامات الجغر افية المعاصرة في الاتجاه الصحيح الذي يلبي ويطاوع حاجة العصر، ويو غل علم

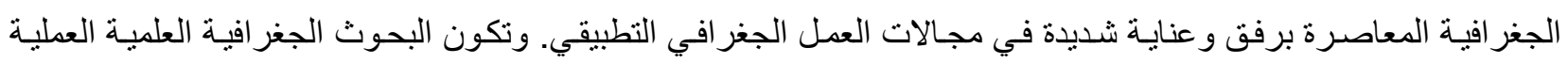
التطبيقية، التي تتوجه إلى الإعلان عن الرأي الجغر افي و هو الذي يرشد الحضور الإنساني والإبداع الحضاري في في أهم مجالات

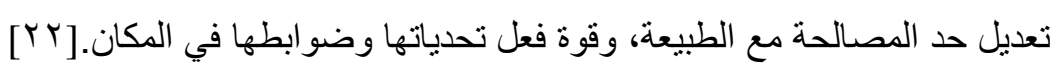
إن الجغر افية المعاصرة هدفها الرئيسي هو التنمية البشرية وجعلها متناغمتا مع البيئة الطبيعية من خـلال استثمار

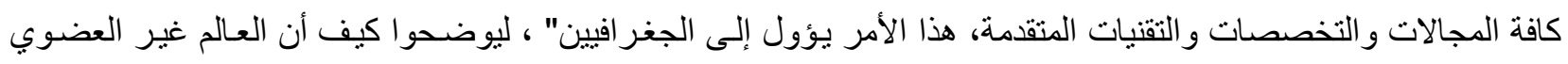

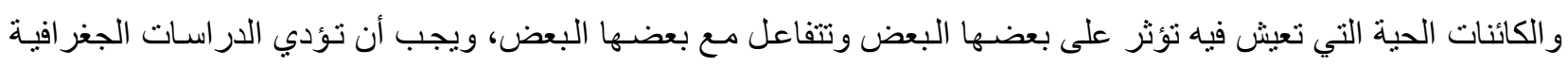

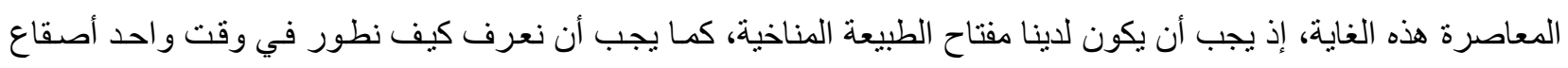

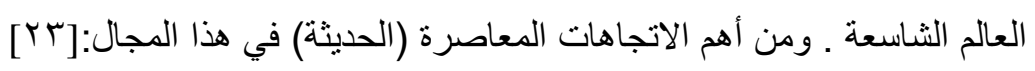


• "در اسة التأثير الدقيق للبيئة على الإنسان" إذ نولى لـه أهميـة كبيرة، و التي من شـأنها أيضـا كثف أسباب تدهور البيئة، من خلال عكس المشكلة، أي دراسة "تأثير الإنسان على البيئة، وبخاصة تدميره للموارد الطبيعية والبشرية " كالتحقيق

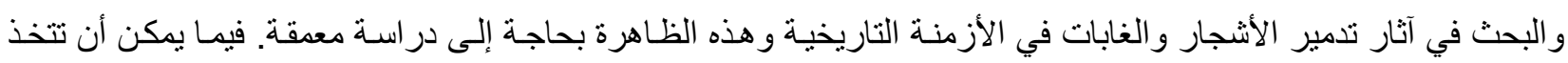

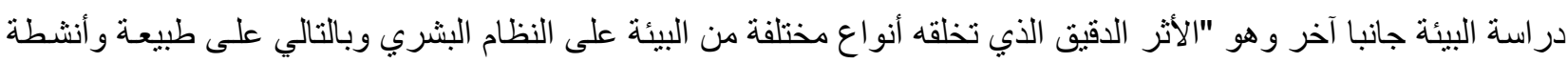
الإنسان" .

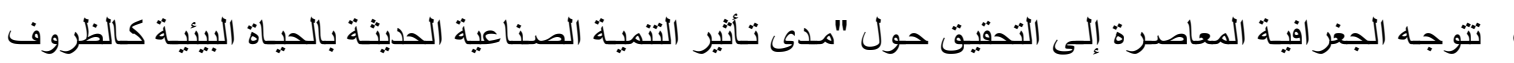

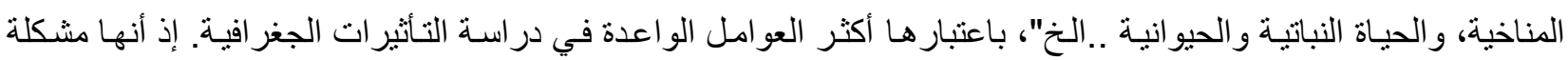
عالمية ينبغي أن تثير اهتمام الجغر افيين في يومنا هذا. هـ مـن الآفاق الواعدة للجغر افيـة المعاصـرة در استها وتخطيطهـا لاستثمار توزيـع الإنسـان على الأرض وتوضيح

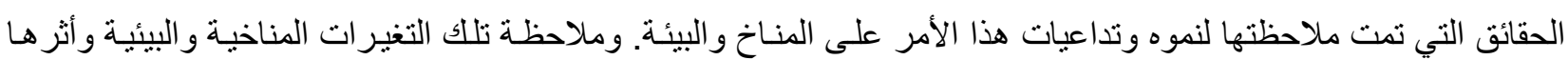
المعكوس على النمو والتوزيع السكاني و هجر اته وحالته الجسدية و العقلية. كما إن الجغر افية اليوم يمكنها أن تدرس المهاجرين الجدد في القارة الأوربية والأمريكية وأماكن أخرى، و آثنار هم

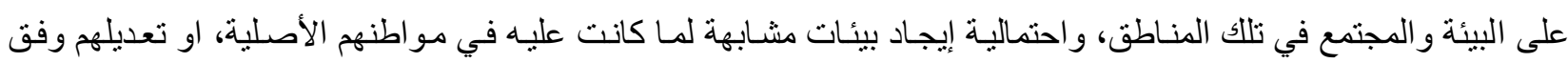
أسلوب حياة الدول المتنبية لهم، وما هو والدور الذي يلعبونه في الحياة الوطنية الجديدة. م و ولا يغفل عنـا أهميـة القارة الأفريقيـة وغناهـا بالذهب و المساس و اليورينيوم و المعـادن النفيسـة، فظـلا عن طبيعتهـا

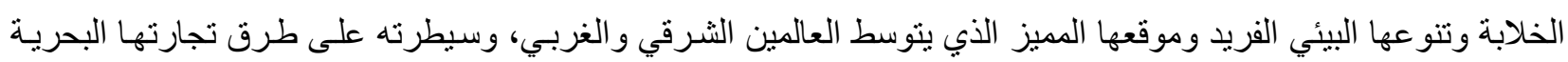

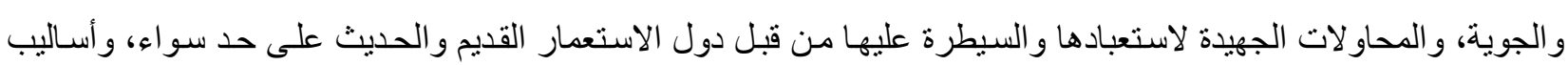

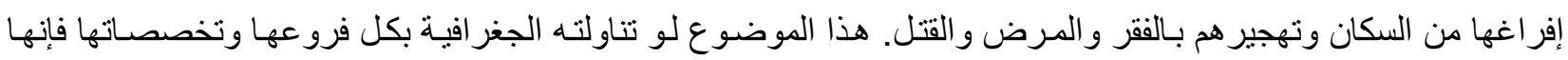
ستنيط اللثام عن اكبر عملية تغيير للجغر افية البشرية والاقتصادية والسياسية والجيوبولتيكية في تاريخ البشرية المعاصر. ه توجه أنظـار عدد من الباحثين الجغر افيين المعاصرين إلى دراسـة الجغر افيـة الحيو انيـة والنباتيـة بسبب قلـة تلك

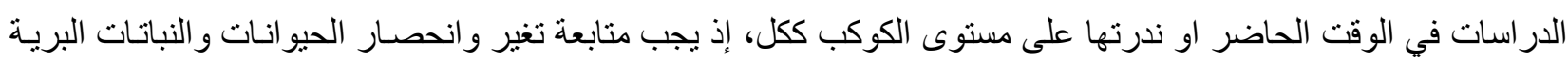

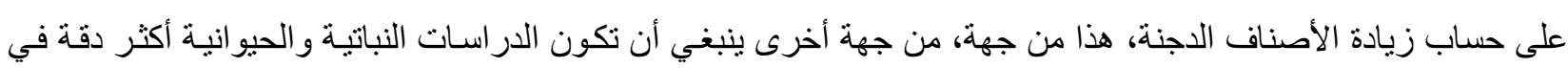

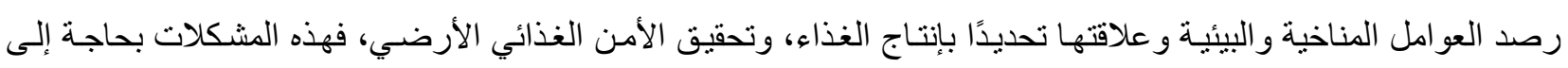
دراسات تفصيلية معدقة تشترك فيها العديد من الحقول المعرفية. • الدراسات الإقليمية يجب أن تتذذ منحًا جديدًا، إذ يجب أن نوجد دراسـات مكثفة في الجغر افية الإقليمية، تمثل خطـا أساسيًا

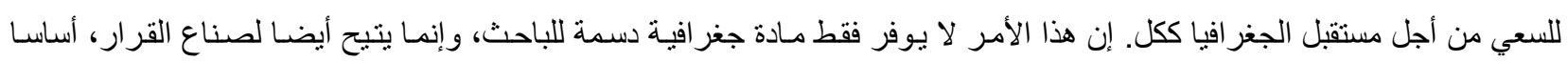

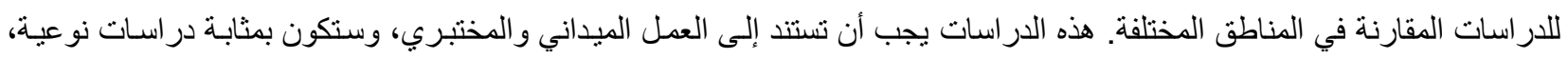

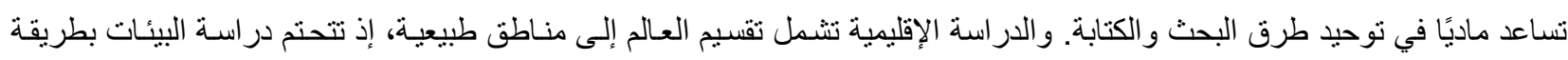

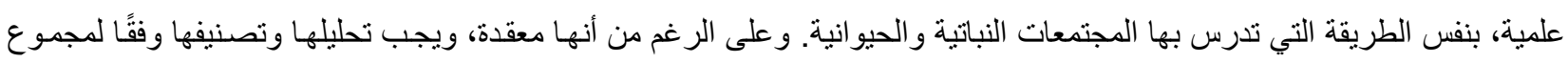

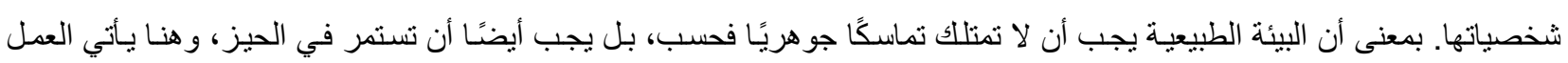

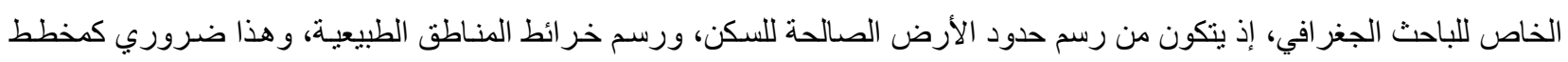

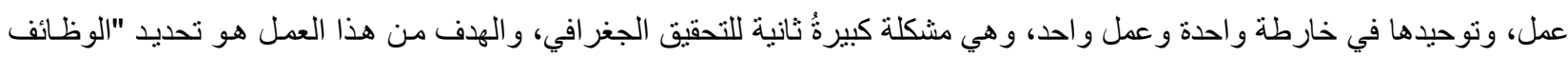




\section{سابعل القفز نمو التطبي.بق العملي وحل مشكلات الواقع:}

إن الفكرة المرتكزة لدى الدارسين عن الجغرافية، هي ما جادت به الأدبيات و المناهج التعليمية في المر احل الدراسية

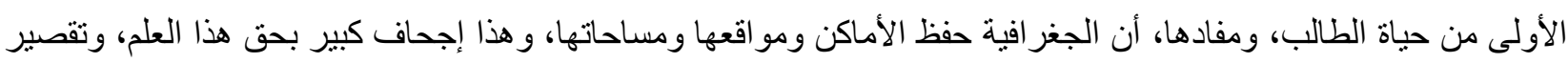

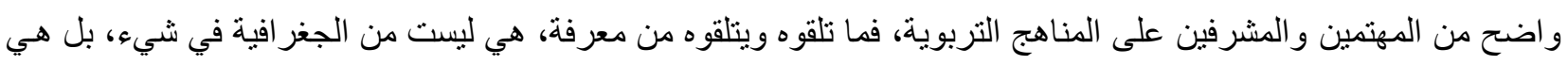

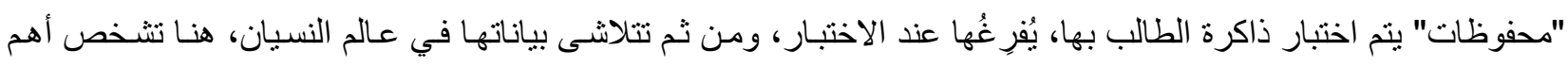

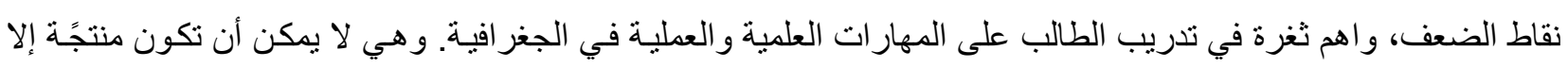

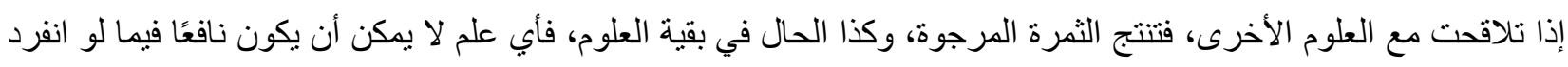
بنفسا، ونأى عن العلوم الأخرى.

إن ما يصادر الجهود الجغر افية، احتسابه ضمن خانة العلوم الإنسانية حصرًا، بـالر غم من رقي تلك العلوم ومكانتها،

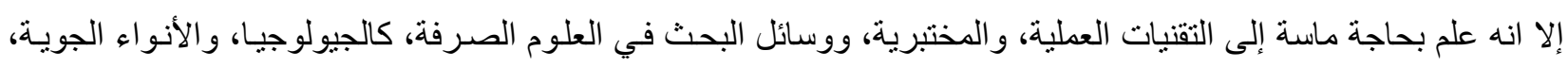

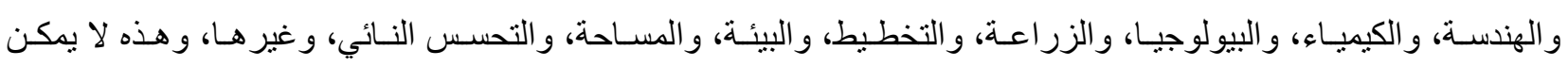

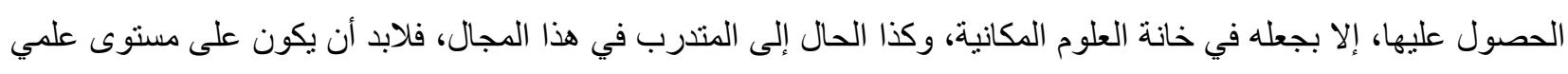

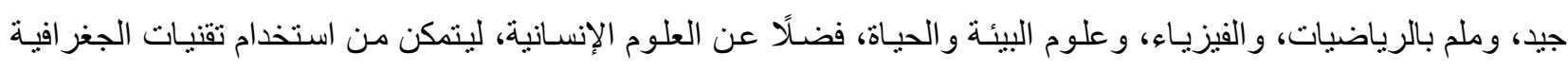

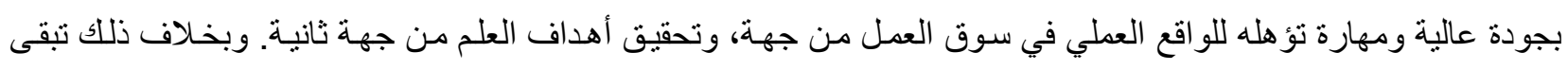

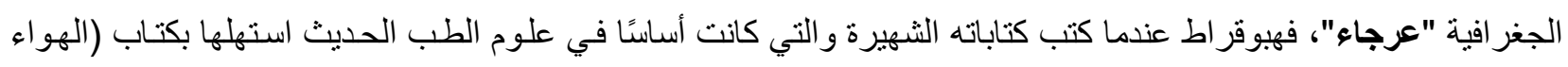

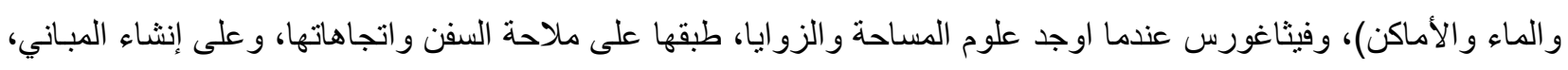

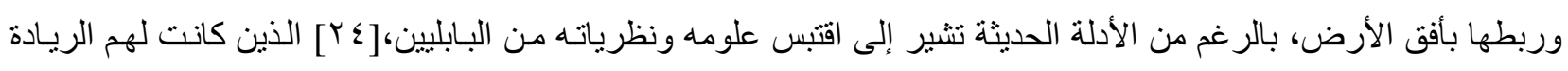

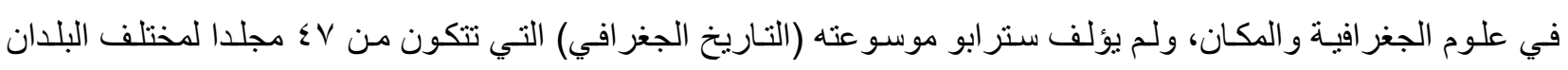

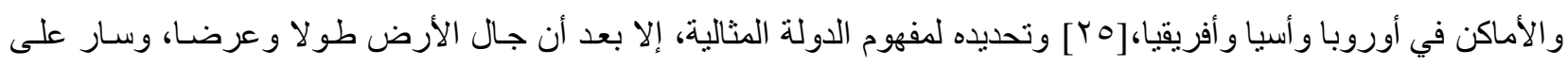

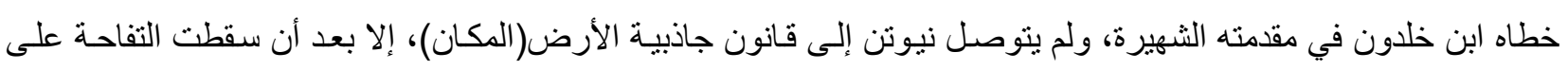

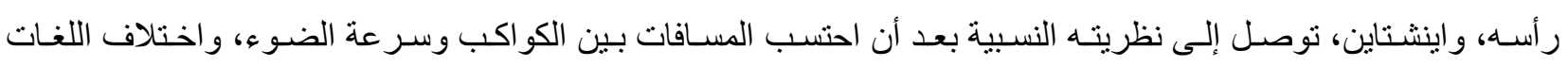

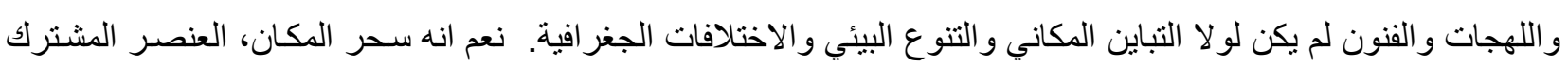

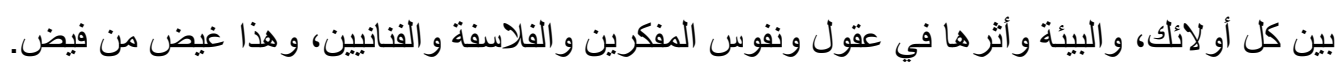

الفاتمة

الجغر افية همزة الوصل بين العلوم الإنسانية والصرفة، وهي تتداخل مـع العلوم المكانية وتقترب منها كثيرا، إلا أن

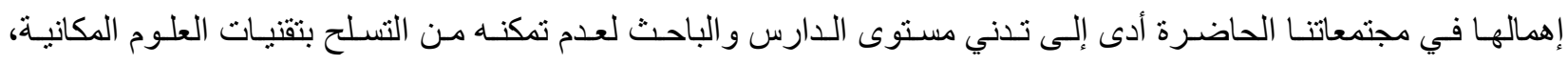

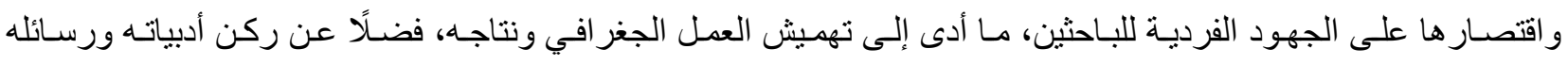

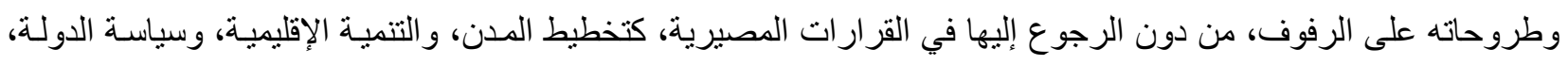

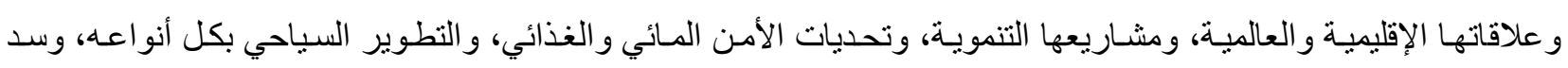

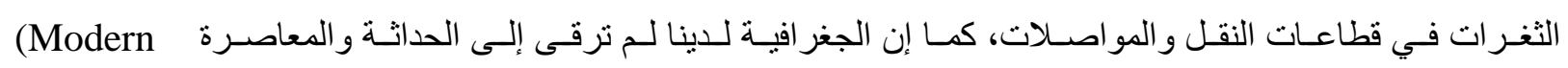
Geography) من جهة أخرى كـان لابد من تطوير مهار ات الجغر افيـة التطبيقيـة كونها الجانب العملي الذي يلبي حاجـة السوق و المؤسسات المختلفة، إلا أن تمسك الجغر افيين بالفروع النظرية المجردة واعتبار ها تخصصات نقية (pure) دون الالتفات إلى 
الجانب المفيد من هذا العلم، زاد رتابة الجغر افية المحلية، فالتطبيق ما هو إلا إنزال النظرية إلى الواقع، و الاستفادة منها لترقى إلى مستوى القانون، ولتحقيق المبادئ الأساسية للعلوم (التتبؤ، والتعميم، والثـمولية) وللاستفادة من المقارنـة في هذا الجانب. ولا نبخس محاو لات الجغر افيين العر اقيين في تطوير وسد الثغرة في هذا الموضوع من حيث أنهم بادروا إلى تعزيز الدراسـات الجغر افية التطبيقية في العديد من الكليات و اعتمادها كأقسام متخصصة، في محاولة لكسر حاجز الرتابة والاعتياد، وهي البذرة المنشودة، إلا أنها لم ترقَ إلى الطموح بعد.

$$
\text { 1 - دراسة وتقييم المناهج الدراسية في المراحل الأولية الخاصة بعلم الجغر افية. }
$$

r- در اسة إمكانية إقرار علم البيئة باعتباره جزئا من الجغر افية وتدريسه في حقول المعرفة الأكاديميـة المختلفة لنشر

$$
\text { الوعي البيئي والجغر افي في أوساط الدارسين. }
$$

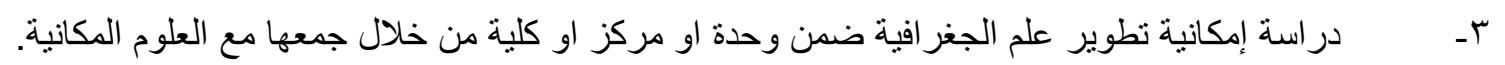

ع - در اسة إمكانية تطوير الأقسام التطبيقية في الجغر افية وجعلها مو اكبة لنظير اتها المتقدمة.

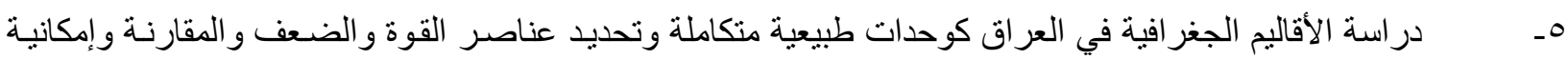

$$
\text { التكامل على المستوى الوطني. }
$$

آ- إعادة در اسة خصائص توزيع السكان في العراق واثر البيئة عليهم من جهة وتدهور ها واثر ذلك على السكان من

$$
\text { النو احي الجسدية و النفسية و العقلية و السلوكية و هجر اتهم. }
$$

V- در اسة إمكانية اعتماد الأدبيات و البحوث الجغر افية في مؤسسات الدولة كمر اجع لحل المشكلات في مجالات البيئة و النقل و الاستخر اج و الاقتصاد و العلاقات الإقليمية و الدولية ومكامن القوة في الدولة ومواطن الضعف و غير ها.

هوامش البمث

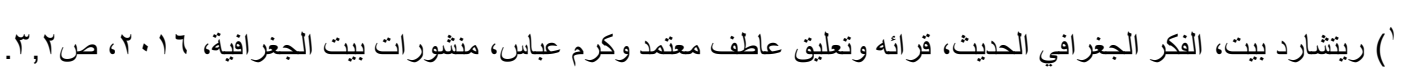

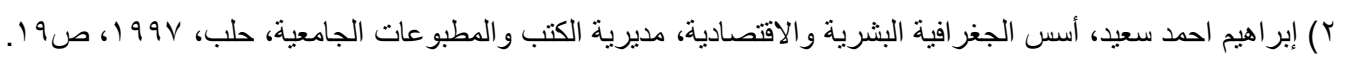

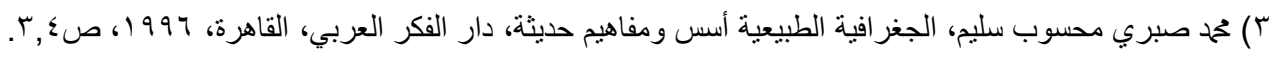

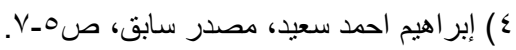

$$
\begin{aligned}
& \text { 0) عبد الرزاق محمد البطيحي، طر ائق البحث الجغر افي، منشورات بيت الحكمة، بغداد، بلا، صلا 10. }
\end{aligned}
$$

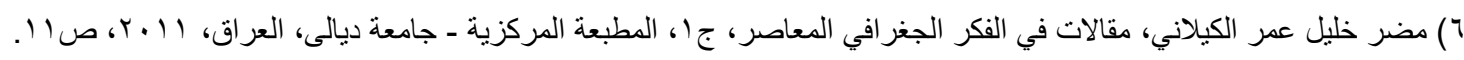

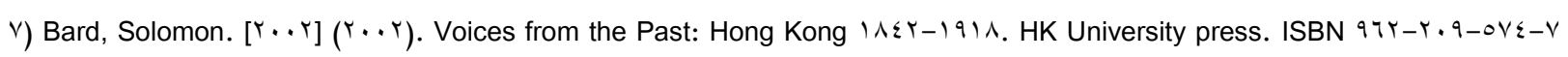

1الأر اضي البحرية|ستصلاح/wiki https://ar.wikipedia.org/wiki

9) راين فاغان، الصيف الطويل، ترجمة د. مصطفى فهمي، سلسلة كتب عالم المعرفة، كتاب . ـ؟، اصدار المجلس الوطني للثقافة والفنون والاداب،

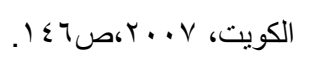

l.) https://en.wikipedia.org/wiki/Early_world_maps\#Babylonian_Imago_Mundi_(ca._tth_c._BCE).

11) Elizabeth M. Craik, The Hippocratic Content And Context, Routedge Taylor \& Francis Group, London and New York, r. 10,pr. 
ir) Melanie Waldron, GEOGRAPHY MATTERS IN ANCIENT EGYPT, raintree, non, $p \leqslant \cdot$.

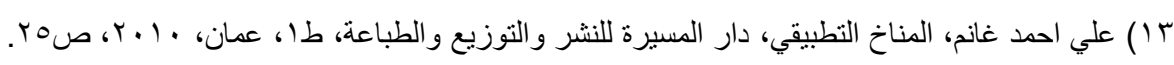

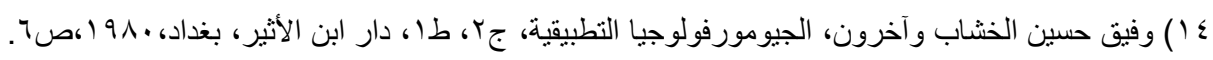

10) https://www.merriam-webster.com/dictionary/industrial\% $\% \cdot$ geography.

7 ( ) كلاوس دودز وديفد اتكنسون، الجغر افية السياسية في مائة عام،جr، ترجمة عاطف معتمد وعزت زيان، المركز القومي للترجمة، المطابع الاميرية،

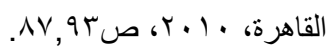

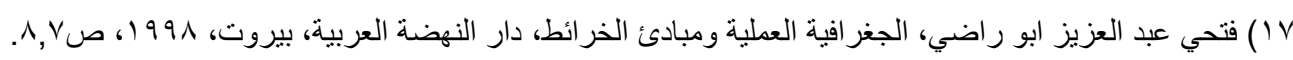

1^) https://en.wikipedia.org/wiki/Geographical_Operations_System.

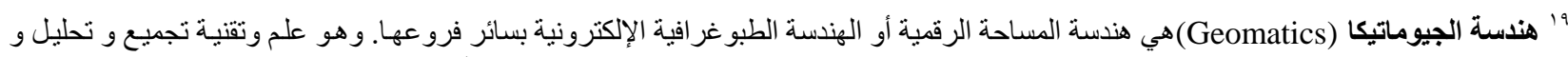

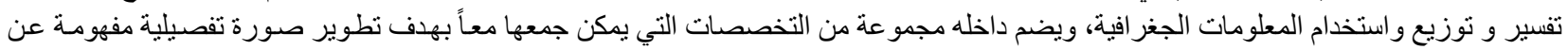

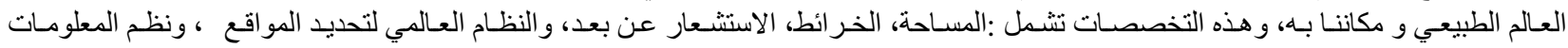

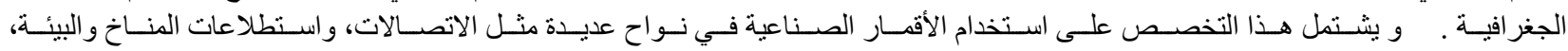

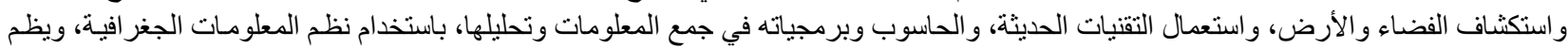

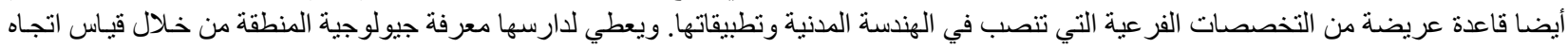

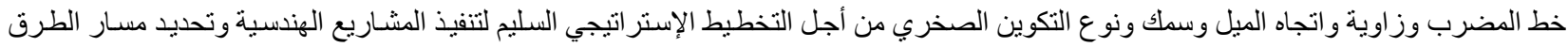

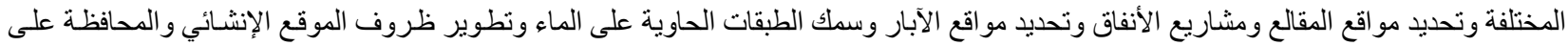

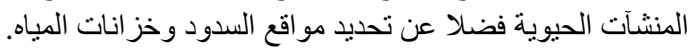

r.) http://www.uodiyala.edu.iq/PageViewer.aspx?id=r·^

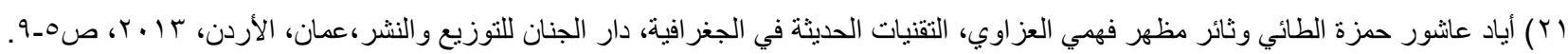

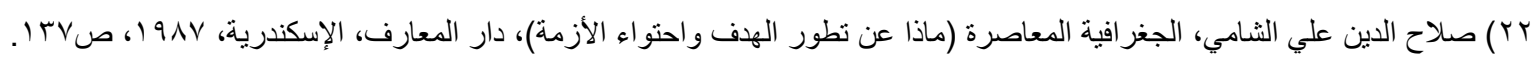

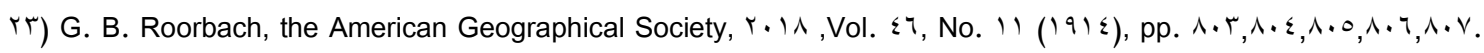
https://www.jstor.org/stable/r. . १ $\leq \wedge$

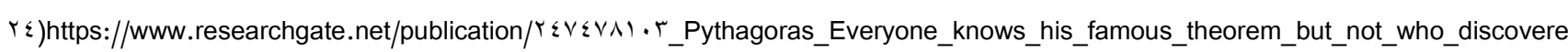
d_it_...._years_before_him

ro) https://la.wikipedia.org/wiki/Geographica_(Strabo) 